\title{
Development of Modified Phenylalanine Ammonia-lyase for the Treatment of Phenylketonuria
}

\author{
Woomi Kıм* \\ Department of Pharmacology, Kosin University College of Medicine, Busan 602-703, Republic of Korea
}

(Received October 9, 2008; Revised December 24, 2008; Accepted December 28, 2008)

\begin{abstract}
Phenylketonuria (PKU) is an inherited metabolic disorder caused by mutations in the phenylalanine catabolic enzyme, phenylalanine hydroxylase (PAH). The use of phenylalanine ammonia-lase (PAL) by oral and parenteral routes as a therapeutic drug for PKU has been severely limited due to inactivation by intestinal proteolysis and immune reactions. PEGylation was applied to PAL to reduce the degrees of antigenicity and proteolytic inactivation. Kinetic experiments with native PAL and pegylated PALs were performed, and $\mathrm{pH}$ stability, temperature stability, and protease susceptibility were evaluated. Enzyme linked immunosorbent assay (ELISA) was carried out to measure the immune complex between pegylated PALs and antiserum that had been extracted from a PAL-immunized mouse. Pegylated PAL, especially branched pegylated PAL (10 kDa, 1:32), was more active for phenylalanine and more stable in pancreatic proteases than native PAL. Native PAL was optimal at $\mathrm{pH} 8.5$, corresponding to the average $\mathrm{pH}$ range of the small intestine; the same finding was noted for pegylated PALs. All linear and branched pegylated PALs had low reactivity with mouse antiserum, especially the 1:16 formulation with linear 5-kDa PEG and the 1:32 formulation with branched 10-kDa PEG. Therefore, we suggest the 1:32 formulation with branched 10-kDa $P E G$ as the most promising formulation for enzyme replacement therapy.
\end{abstract}

Keywords: Phenylketonuria (PKU), Phenylalanine ammonia-lyase (PAL)

\section{INTRODUCTION}

Phenylketonuria (PKU) is an inherited metabolic disorder caused by mutations in the phenylalanine catabolic enzyme, phenylalanine hydroxylase (PAH) (Scriver and Kaufman, 2001). A few studies have focused on the application of phenylalanine ammonia-lyase (PAL) for enzyme replacement therapy for patients with PKU (Hoskins and Gary, 1982). In 1980, Hoskins and colleagues reported their initial trials of the use of PAL from Rhodotorula glutinis for PKU enzyme substitution applications (Hoskins et al., 1980). However, native PAL is very susceptible to protease inactivation (Gilbert and Jack, 1981; Gilbert and Tully, 1985) and the sensitivity of PAL to protease inactivation or low activity in gastric conditions limits further development of native PAL as a clinical therapeutic (Gilbert and Jack, 1981). Sarkissian et al. considered the parenteral application of PAL for reducing the plasma con-

${ }^{*}$ Corresponding author

Tel: +82-51-990-6437 Fax: +82-51-990-3084

E-mail: kwm@ns.kosinmed.or.kr centration of phenylalanine (Sarkissian et al., 1999). They reported that intraperitoneal injections of unmodified PAL lowered blood L-phenylalanine levels in the PKU model, but repeated injections led to immunogenic reductions in efficacy due to elicitation of an immune response.

Various formulations have been tested to prevent protease inactivation or to suppress the immunogenicity of PAL (Ambus et al., 1983; Bourget and Chang, 1984; Bourget and Chang, 1989; Chang et al., 1995). Microencapsulated PAL in artificial cells administered orally to rats with PKU was more effective than a phenylalanine-free diet (Bourget and Chang, 1989). However, the restriction was that microencapsulated PAL demonstrated activity that was only $20 \%$ of native PAL enzyme activity (Bourget and Chang, 1986). This would be limited to patients with mild PKU, and thus diet control should be recommended as therapy (Fritz et al., 1976). Therefore, the most important condition during-modification was maintaining enzyme activity in addition to protection from pancreatic proteolysis and/or immune reaction to effectively function in reducing phenylalanine levels. 
Under these circumstances, one approach to overcome the reduction in the activity of PAL might be the use of PEGylation derivatization, since the covalent coupling of activated PEG molecules to the protein (PEGylation) has been shown to allow retention of bioactivity, and even increases circulation half-times (Delgado et al., 1992; Mehvar, 2000; Veronese et al., 2002; Greenwald et al., 2003; Harris and Chess, 2003). A growing number of pegylated enzymes are being approved by the FDA (Harris and Chess, 2003). Thus, PEGylation can also be applied to PAL. In this study, we generated PAL: PEG-conjugates to investigate whether pegylated PAL can maintain its enzymatic activity and protect itself from degradation by pancreatic proteases and/or immune reactions.

\section{MATERIALS AND METHODS}

\section{PEGylation}

PEG: PAL conjugates were produced by coupling either linear 5-20 kDa methoxy-PEG-SPA or 10-40 kDa branched methoxy-(PEG) $)_{2}-\mathrm{NHS}$ (Nektar Therapeutics) to PAL (Hershfield et al., 1991). The concentration of PAL in the reaction mixture was $1 \mathrm{mg} / \mathrm{ml}$ in $50 \mathrm{mM}$ potassium phosphate buffer, pH 8.5. Pegylated PAL was analyzed by sodium dodecyl sulfate-polyacrylamide gel electrophoresis (SDS-PAGE) using $10 \%$ Bis-Tris gels in 3-( $N$-morpholino) propane sulfonic acid (MOPS) buffer.

\section{PAL activity assay}

The activity of PAL/ -pegylated PAL using L-phenylalanine as a substrate was assayed at room temperature by measuring the production of trans-cinnamic acid, which was monitored by the increase in absorbance at $290 \mathrm{~nm}$ (Hoskins, 1968). The reaction mixture contained $22.5 \mathrm{mM}$ phenylalanine in $100 \mathrm{mM}$ Tris-HCl buffer, $\mathrm{pH}$ 8.5. The molar extinction coefficient of trans-cinnamic acid at $290 \mathrm{~nm}$ is $10.238 \mathrm{~L} \cdot \mathrm{M}^{-1} \cdot \mathrm{cm}^{-1}$.

\section{Kinetic analysis}

Kinetic experiments were performed on a Cary UV spectrophotometer (Cary 50). All experiments were conducted at room temperature. For standard measurements, the final enzyme concentration was $0.0035 \mathrm{mg} / \mathrm{ml}$, but for kinetic studies the enzyme concentration in the assay was adjusted so that the slope at $290 \mathrm{~nm}$ per minute was in the range of 0.005 to 0.02 . The velocity of the reaction $(v)$ is the number of substrate molecules converted to trans-cinnamic acid per minute.

\section{Temperature and $\mathrm{pH}$ stabilities of PAL}

Native PAL and pegylated PAL $(1 \mathrm{mg} / \mathrm{ml})$ were stored at $4^{\circ} \mathrm{C}$ and $-80^{\circ} \mathrm{C}$ in closed bottles and the residual enzyme activity was measured for 6 months. The PAL or pegylated $\mathrm{PAL}$ was incubated in $100 \mathrm{mM}$ Tris-Cl buffer of $\mathrm{pH} 7.5$ or $\mathrm{pH} 8.5$, at $37^{\circ} \mathrm{C}$ for 0 to -200 hours. After incubation, substrate solutions containing $22.5 \mathrm{mM} \mathrm{L}$-phenylalanine in 100 $\mathrm{mM}$ Tris- $\mathrm{Cl}$ buffer were added and incubated at $37^{\circ} \mathrm{C}$ for the assay. The production of trans-cinnamic acid was monitored at $290 \mathrm{~nm}$.

\section{Protease susceptibility}

To evaluate the effects of pancreatic proteases on PAL and pegylated PAL activities, the enzymes $(0.9 \mathrm{mg} / \mathrm{ml})$ in $100 \mathrm{mM}$ Tris- $\mathrm{Cl}$ buffer at $\mathrm{pH} 8.5$ were incubated with the protease mixture at $37^{\circ} \mathrm{C}$ for 1 hour. The pancreatic protease mixture contained trypsin $(20 \mu \mathrm{g} / \mathrm{ml})$, chymotrypsin $(30 \mu \mathrm{g} / \mathrm{ml})$, carboxypeptdase A $(20 \mu \mathrm{g} / \mathrm{ml})$, and carboxypeptidase B $(30 \mu \mathrm{g} / \mathrm{ml})$, elastase $(10 \mu \mathrm{g} / \mathrm{ml})$. Samples of $50 \mu \mathrm{l}$ were collected every 10 minutes and for the residual PAL activity. At the same time intervals, samples of $100 \mu \mathrm{l}$ were collected and subjected to SDS-PAGE.

\section{ELISA}

The ELISA plate (Nunc Maxisorp) was coated with purified native PAL or pegylated PAL $(2-8 \mu \mathrm{g} / \mathrm{ml}$ in Tris-Cl buffer, $\mathrm{pH} 8.5$ ) for 2 hours at $37^{\circ} \mathrm{C}$. Antisera for positive control were obtained from wild PAL-treated mice and were diluted $0-5,000$ fold. Negative control serum was prepared by sampling from a buffer-treated mouse. HRP-Goat anti-mouse IgG $(1: 2,500,50 \mu \mathrm{l})$ was used as the secondary antibody. Absorbance was measured at $450 \mathrm{~nm}$, and antibody (Ab) titer expressed as $\mathrm{OD} / \mu \mathrm{l}$, which was calculated as $A(450 \mathrm{~nm}) \times$ dilution factor $/ 100 \mu \mathrm{l}($ Bos et al., 1981).

\section{Statistical analysis}

The data were analyzed using the unpaired or paired Student's $t$-test, and values were considered significantly different when the $p$ value was $<0.05$. One-way analyses of variances were tested, and non-significant differences between the groups, which presented as same letters, were followed by Tukey's multiple comparison test. The results are expressed as mean \pm SEM.

\section{RESULTS}

\section{Activity of native PAL and pegylated PAL}

The reaction velocities $(v)$ of native PAL and pegylated PAL were dose-dependent at phenylalanine concentration ranges from 0.02 to $11.25 \mathrm{mM}$. The $V_{\max }$ values of native 


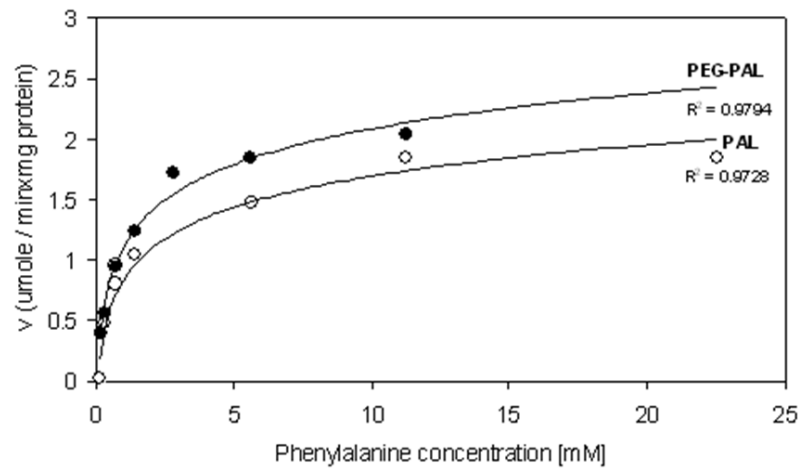

Fig. 1. Activity of native PAL and pegylated PAL on phenylalanine. The activity of native PAL and branched pegylated PAL (10 $\mathrm{kDa}, 1: 32)$ on phenylalanine $(0-25 \mathrm{mM})$ was assayed by measuring the production of trans-cinnamic acid, which was monitored as the increase in the absorbance at $290 \mathrm{~nm}$.

Table I. The specific activity of native PAL and pegylated PAL

\begin{tabular}{lc}
\hline \multicolumn{1}{c}{ Enzyme } & $\begin{array}{c}\text { Specific activity } \\
(\mu \mathrm{mole} / \mathrm{min} \cdot \mathrm{mg} \text { protein })\end{array}$ \\
\hline Native PAL & $1.77 \pm 0.03$ \\
Pegylated PAL & $1.79 \pm 0.09$ \\
$\quad$ Linear PEG, $5 \mathrm{kDa}(1: 8)$ & $1.84 \pm 0.05$ \\
Linear PEG, $20 \mathrm{kDa}(1: 2)$ & $1.89 \pm 0.18$ \\
Branched PEG, $10 \mathrm{kDa}(1: 28)$ & $2.03 \pm 0.06$ \\
Branched PEG, $10 \mathrm{kDa}(1: 32)$ &
\end{tabular}

Data are expressed as mean \pm SEM $(n=5, p<0.05)$.

PAL and pegylated PAL were 1.77 and $2.03 \mu \mathrm{mole} / \mathrm{min}$. mg protein, respectively. The $\mathrm{K}_{\mathrm{m}}$ of native PAL was $4.77 \times$ $10^{-4} \mathrm{M}$ and that of pegylated PAL was $3.61 \times 10^{-4} \mathrm{M}$ (Fig. 1). The specific activity of all pegylated PALs was higher than that of native PAL (Table I). Branch pegylated PAL (10 $\mathrm{kDa}, 1: 32)$ had the strongest activity for phenylalanine.

\section{Temperature and $\mathrm{pH}$ stabilities}

Native PAL $(1 \mathrm{mg} / \mathrm{ml})$, stored at $-80^{\circ} \mathrm{C}$ for 20 weeks, possessed $87 \%$ of its original activity. In contrast to native PAL, all linear pegylated PALs showed no loss of activity. Two different molar ratios of branched pegylated PAL possessed $85 \%$ (10 kDa, 1:28) and 97 percent (10 kDa, 1:32) of the original activity. Although PAL had an optimum $\mathrm{pH}$ at 8.5 , when it was incubated for 150 hours at $37^{\circ} \mathrm{C}$, only $61.56 \%$ of the original activity remained. Native PAL at pH 7.5 was more stable than native PAL at pH 8.5 after 150 hours of incubation at $37^{\circ} \mathrm{C}$ (Fig. 2). Pegylated PAL was also optimal at $\mathrm{pH} 8.5$ and pegylated PAL had similar stability to native PAL at pH 7.5. Below pH 5.5, native PAL and pegylated PAL possessed $33 \%$ and $27 \%$ of their activity, respectively, after 1 week.

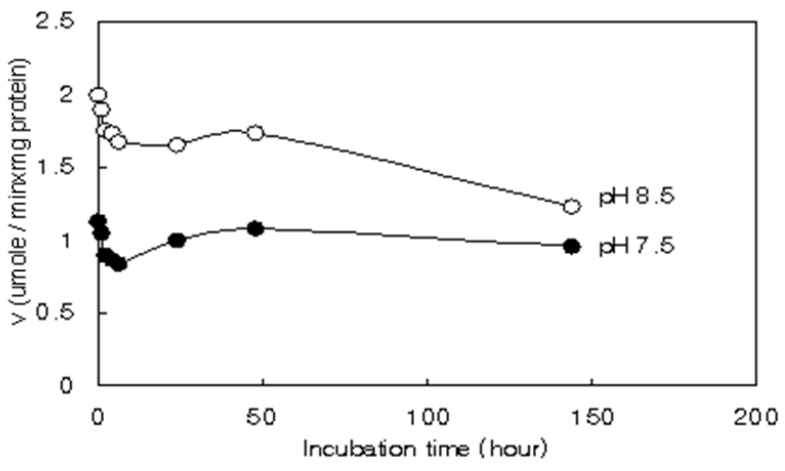

Fig. 2. The stability of native PAL at $\mathrm{pH} 7.5$ or 8.5 . Native $P A L$ was incubated in $100 \mathrm{mM}$ Tris-Cl buffer of $\mathrm{pH} 7.5$ or 8.5 at $37^{\circ} \mathrm{C}$. After incubation, a substrate solution containing $22.5 \mathrm{mM}$ L-phenylalanine in $100 \mathrm{mM}$ Tris- $\mathrm{Cl}$ buffer was added and incubated at $37^{\circ} \mathrm{C}$ for the assay. The production of transcinnamic acid was monitored at $290 \mathrm{~nm}$.

Table II. Protease susceptibilities of PAL and pegylated PALs

\begin{tabular}{lcc}
\hline \multicolumn{1}{c}{ Enzyme } & Residual activity $(\%)^{\mathrm{a}}$ & $\mathrm{T}^{\mathrm{b}, \mathrm{c}}$ \\
\hline Native PAL & 0 & $\mathrm{a}$ \\
$\begin{array}{l}\text { Pegylated PAL } \\
\quad \text { Linear PEG, 5 kDa (1:8) }\end{array}$ & $15.62 \pm 5.08$ & $\mathrm{~b}$ \\
$\quad$ + linear PEG, 20 kDa (1:2) & & \\
$\quad$ Linear PEG, 20 kDa (1:2) & $16.19 \pm 1.41$ & $\mathrm{~b}$ \\
$\quad$ Branched PEG, 40 kDa (1:2) & $51.22 \pm 4.71$ & $\mathrm{c}$ \\
$\quad$ Branched PEG, 10 kDa (1:28) & $43.75 \pm 3.10$ & $\mathrm{c}$ \\
$\quad$ Branched PEG, 10 kDa (1:32) & $75.71 \pm 4.85$ & $\mathrm{~d}$ \\
\hline
\end{tabular}

${ }^{\mathrm{a}}$ The residual activity of native PAL and pegylated PAL was calculated by measuring the remaining activity after incubation with the pancreatic protease mixture for 10 minutes at $37^{\circ} \mathrm{C}$. Data are expressed as mean \pm SEM $\left(n=5,{ }^{b} p<0.01\right)$. Statistical significances were tested by one-way analysis of variances among

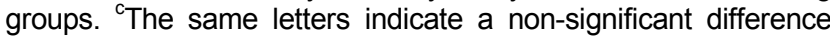
between groups on the basis of Tukey's multiple comparison test.

\section{Protease susceptibility}

After incubation with the pancreatic proteases mixture for 10 minutes at $37^{\circ} \mathrm{C}$, native PAL showed no activity (Table II). In contrast to native PAL, 5 pegylated PALs maintained their activity, with the amount of residual activity (\%) varying from 19.14 to 73.37 (Table II). Branched pegylated PAL (10 kDa, 1:32) was the most effective in maintaining its activity in the pancreatic protease mixture (Table II). The experiments with SDS-PAGE showed different patterns of bands (Fig. 3). Compared to the bands of native PAL and pegylated PAL with Tris-Cl buffer, the bands of native PAL and pegylated PALs with pancreatic proteases were more and moved lower from the original bands (Fig. 3). In addition, more bands with smaller molecular weights appeared after 30 minutes of incubation (Fig. 3). 
A

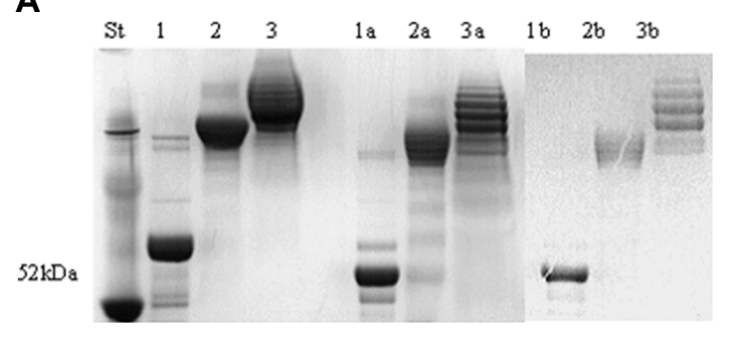

B

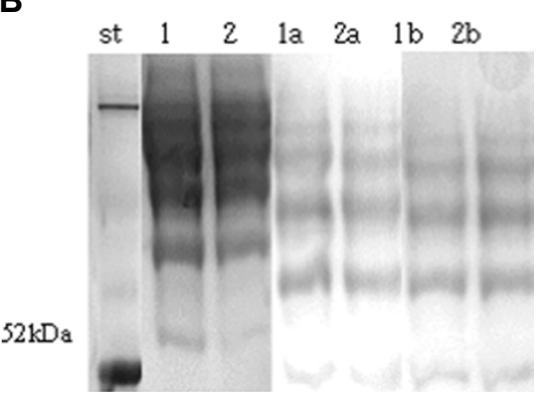

Fig. 3. Digestions of linear and branched pegylated PALs by pancreatic proteases on SDS-PAGE. (A) Native PAL and linear pegylated PALs $(0.9 \mathrm{mg} / \mathrm{ml})$ in $100 \mathrm{mM}$ Tris-Cl buffer at $\mathrm{pH} 8.5$ were incubated with reaction buffer $(1,2,3)$ or the protease mixture $(1 \mathrm{a}, 2 \mathrm{a}, 3 \mathrm{a}, 1 \mathrm{~b}, 2 \mathrm{~b}, 3 \mathrm{~b})$ at $37^{\circ} \mathrm{C}$ for 0 to -30 minutes. After $10(1 a, 2 a, 3 a)$ or $30(1 b, 2 b, 3 b)$ minutes of incubations, $100 \mu$ of each sample was analyzed by SDS-PAGE on $4-10 \%$ Bis-Tris gels. St: High-molecular-weight, standard marker, 1: native PAL, 2: 5-kDa linear pegylated PAL (1:32), 3: 20-kDa linear pegylated PAL (1:8). (B) Branched pegylated PALs $(0.9$ $\mathrm{mg} / \mathrm{ml}$ ) in $100 \mathrm{mM}$ Tris-Cl buffer at $\mathrm{pH} 8.5$ was incubated with reaction buffer $(1,2)$ or the protease mixture $(1 a, 2 a, 1 b, 2 b)$ at $37^{\circ} \mathrm{C}$ for 0 to -30 minutes. After $10(1 \mathrm{a}, 2 \mathrm{a})$ or $30(1 \mathrm{~b}, 2 \mathrm{~b})$ minutes of incubations, $100 \mu$ lo each sample was analyzed by SDS-PAGE on $4-10 \%$ Bis-Tris gels. St: High-molecularweight, standard marker, 1: 10-kDa branched pegylated PAL (1:28), 2: 10-kDa branched pegylated PAL (1:32).

Two branched pegylated PALs retained their activity in the pancreatic proteases mixture longer than native PAL (Fig. 4). After 1 minute of incubation in the pancreatic protease mixture, the residual activity of native PAL decreased to less than $30 \%$. On the other hand, branched pegylated PAL (10 kDa, 1:32) kept its activity rate higher than $50 \%$ even after 30 minutes of incubation with the pancreatic protease mixture (Fig. 4).

\section{ELISA}

This graph showed a linear dose-dependent line for positive control. The absorbance increased proportionally to the dilution factors of positive control. For negative control, the absorbance showed a steady and flat line (Fig. 5).

As shown in Fig. 6 and Fig. 7, all linear and branched pegylated PAL showed strong protections against immune

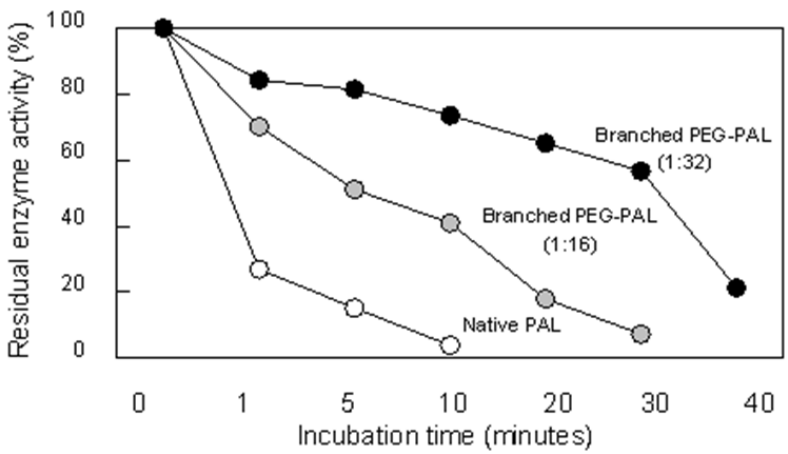

Fig. 4. Inactivation of branched pegylated PAL by pancreatic proteases. The residual enzyme activity of native PAL and branched pegylated PAL was calculated by measuring the remaining activity after incubation with the pancreatic protease mixture for $0-40$ minutes at $37^{\circ} \mathrm{C}$. Branched PEG (10 kDa) was used for PEGylation of native PAL.

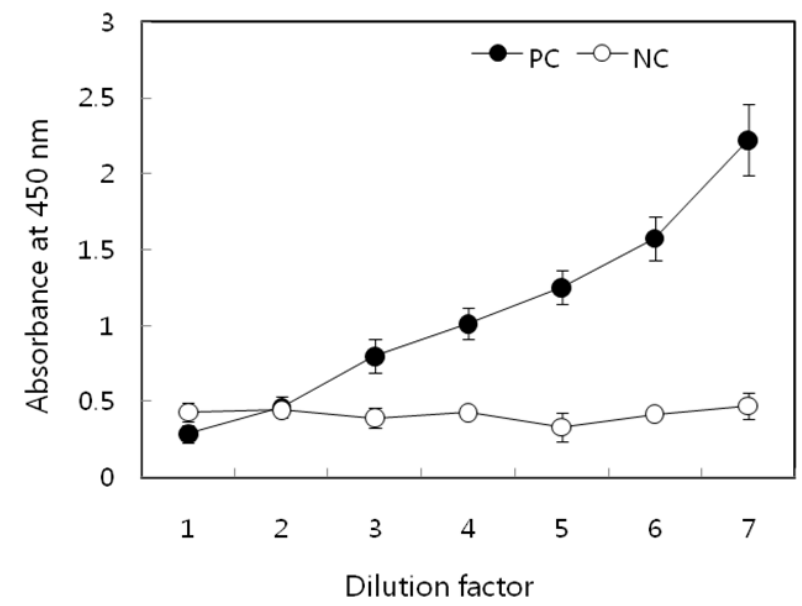

Fig. 5. Dilution linearity for ELISA. PC: positive control (antisera from native PAL-treated-mice), NC: negative control (antisera from buffer-treated-mice). Antisera were diluted to the concentrations of $0-1 / 5,000$. Dilution factors were represented as $1(0), 2$ (1:160,000), $3(1: 80,000), 4(1: 40,000), 5(1: 20,000)$, $6(1: 10,000)$, and $7(1: 5,000)$. Data are expressed as mean \pm SEM $(p<0.05)$.

reactions compared to native PAL. All linear pegylated PAL showed little reaction to the antibody (Fig. 6).

All branched pegylated PALs showed little reaction with the antibody, especially branched pegylated PAL (10 kDa, 1:32) (Fig. 7).

As the coated enzyme concentrations of native PAL and branched pegylated PAL increased higher from $2 \mu \mathrm{g}$ to 8 $\mu \mathrm{g}$, the immune reaction between the native PAL and the antibody as positive control increased. As for the two branched pegylated PALs, their reactions were not enhanced despite the increase in enzyme concentration 


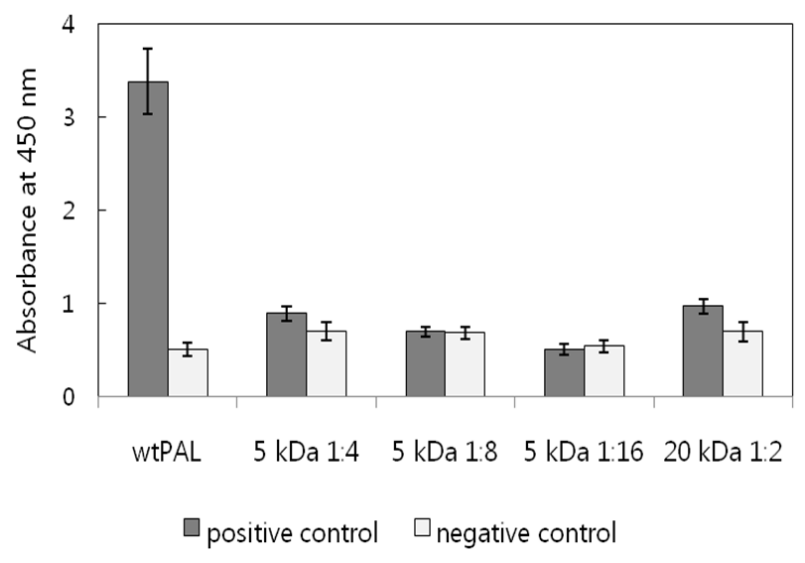

Fig. 6. ELISA of linear pegylated PAL. The ELISA plate was coated with $8 \mathrm{ug} / \mathrm{ml}$ of wild PAL or linear pegylated PAL in Tris-Cl buffer, $\mathrm{pH} 8.5$, for 2 hours at $37^{\circ} \mathrm{C}$. Antisera for positive control were obtained from a native PAL-treated-mice and diluted 5,000 -fold. Negative control serum was prepared by sampling from buffer-treated-mice. Data are expressed as mean \pm SEM $(p<0.005)$.

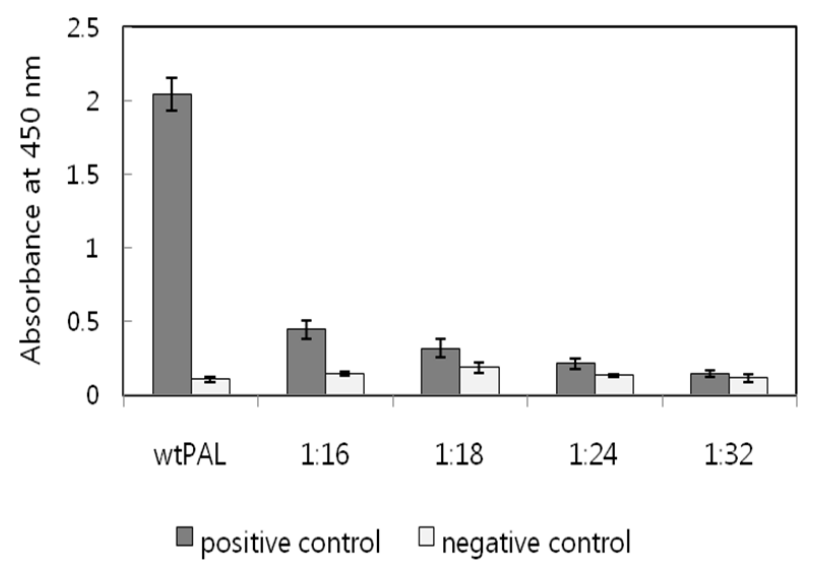

Fig. 7. ELISA of branched pegylated PAL. The ELISA plate was coated with $4 \mathrm{mg} / \mathrm{ml}$ of wild PAL or $10 \mathrm{kDa}$ of branched pegylated PAL in Tris-Cl buffer, $\mathrm{pH} 8.5$, for 2 hours at $37^{\circ} \mathrm{C}$. Antisera for positive control were obtained from native PALtreated-mice and diluted 5,000-fold. Negative control serum was prepared by sampling from buffer-treated-mice. Data are expressed as mean \pm SEM $(p<0.001)$.

(Fig. 8).

\section{DISCUSSION}

The use of PAL as a therapeutic drug for PKU via the oral and parenteral routes has been severely limited due to inactivation by intestinal proteolysis and immune reactions. In this paper, PEGylation was applied to PAL to reduce the degree of immune reaction and proteolytic inactivation

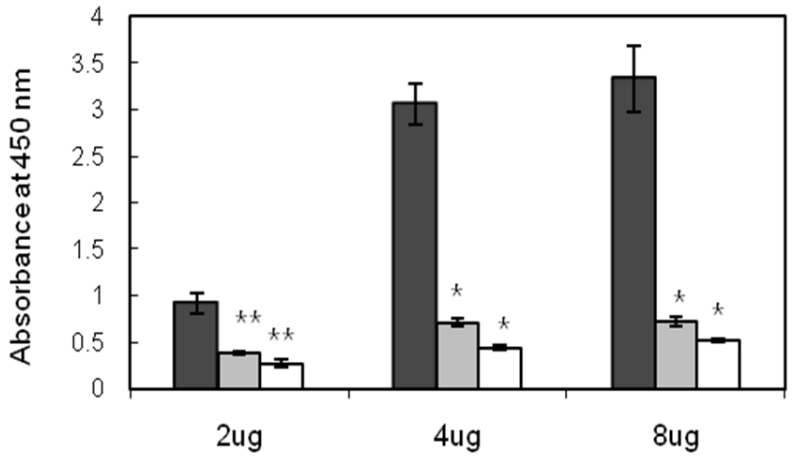

Enzyme concntration

口wtPAL aBranch PEG 10kD 1:28 aBranch PEG 10kD 1:32

Fig. 8. ELISAs for different concentrations of PAL and branched pegylated PAL. The ELISA plate was coated with 2-8 $\mu \mathrm{g} / \mathrm{ml}$ of wild PAL or branched pegylated PAL in Tris-Cl buffer, $\mathrm{pH} 8.5$, for 2 hours at $37^{\circ} \mathrm{C}$. Antisera were obtained from wild PAL-treated-mice and diluted 5,000-fold. Data are expressed as mean $\pm \operatorname{SEM}\left({ }^{*} p<0.001,{ }^{* *} p<0.01\right)$.

while maintaining PAL activity. Because all the lysine residues (29) of PAL are on the surface of the molecule (Monfardini et al., 1995; Veronese et al., 1996; Veronese, 2001), it was presumably available for PEGylation and easy to conduct experiments with a variety of molar ratios during PEGylation. All the pegylated forms of PAL were retained to some extent and possessed increased catalytic activity compared to native PAL (Table 1). Especially, branched pegylated PAL (10 kDa, 1:32) showed an increased $V_{\max }$ value and a decreased $K_{m}$ value (Fig. 1). We also tested resistance against pancreatic proteases by comparing the activities of linear and branched pegylated PAL to that of native PAL. All pegylated PALs were more stable in the pancreatic protease mixture than native PAL (Table 2). Branched pegylated PAL (10 kDa, 1:32) showed the strongest protective effect against proteolysis (Table 2), although the effect was not retained for more than 50 minutes (Fig. 4). From these results, PEGylation did not consistently protect PAL from intestinal proteolysis, and therefore, more advanced modification of PAL should be developed.

It was important to test the stability of the activity under the physiologic condition to use PAL for enzyme replacement therapy. PAL was optimal at $\mathrm{pH} 8.5$, corresponding to the average $\mathrm{pH}$ range of the small intestine, and the activity of pegylated PAL was similar to that of native PAL at $\mathrm{pH}$ 8.5. This indicates that PAL has an advantage when it is administered through an oral route and so does pegylated PAL. However, the activity of native and pegylated PAL dropped below pH 5.5. The activity of pegylated PAL may not be stable against gastric acidity of $\mathrm{pH}$ 2.2. Hoskins 
suggested an encapsulated PAL for bypassing the stomach, although it showed a lower activity than native PAL (Hoskins et al., 1980). Unfortunately, the reduced activity of the encapsulated PAL was not enough to control the plasma phenylalanine level in PKU. Encapsulation needed additional processes to enhance the activity of PAL for oral administration. Thus, PEGylation with encapsulation may be recommended, since the activity of PAL could be enhanced by pegylation and gastric degradation could be protected by encapsulation.

On the other hand, we had to overcome some problems related to PAL's immunogenicity for parenteral administration (Fritz et al., 1976). For the quantitation of the immune complex between pegylated PAL and antibody, ELISA was carried out. As shown in Figs. 6 and 7, all linear and branched pegylated PALs had low reactivity with the mouse antiserum, especially the 1:16 formulation with linear 5-kDa PEG and the 1:32 formulation with branched 10-kDa PEG (Fig. 8). The data indicated that all PEGs shielded the PAL's surface to abrogate antibody binding to PAL, and, therefore, PEGylation of PAL almost completely attenuated immunoreactivity. Branched PEG, which is characterized by two linear PEG chains with one reactive group, has recently been developed (Monfardini et al., 1995; Veronese et al., 1996; Veronese, 2001). The bulky branched structure of PEG probably may not allow the pancreatic protease to reach the protein surface, which is why it can protect partially itself against the pancreatic protease's attack partially (Table 2). Of all branched pegylated PAL in our experiments, $10 \mathrm{kDa}$ of branched pegylated PAL (1:32) was the most effective in protecting itself from immunogenicity, although the protection against pancreatic proteolysis was not perfect. Therefore, we suggest that the 1:32 formulation with branched 10-kDa pegylated PAL is the most promising formulation for enzyme replacement therapy.

In conclusion, pegylated PAL might be a useful pretreatment modality for increasing or maintaining PAL's catalytic activity while effectively protecting itself from degradation by immune reactions. Pegylated PALs, especially branched PEG-PAL (10 kDa, 1:32), should be further evaluated both in vitro and in vivo, in order to assess its potential use in the treatment of human PKU patients. PEGylation may provide a new prospect for both oral and parenteral PAL therapies for patients with PKU.

\section{ACKNOWLEDGMENTS}

The author thanks to Alejandra Gamez for her perfect experimental support on pegylation and Raymond C.
Stevens for his invaluable advice. I am grateful to the PKU team at department of molecular biology, Scripps Research Institute.

\section{REFERENCES}

Ambrus, C. M. et al. (1983). In vivo safety of hollow fiber enzyme-reactors with immobilized phenylalanine ammonialyase in a large animal model for phenylketonuria. $J$. Pharmacol. Exp. Ther. 224, 598-602.

Bos, E. S., van der Doelen, A. A., van Rooy, N. and Schuurs, A. H. (1981). 3,3',5,5' -Tetramethylbenzidine as an Ames test negative chromogen for horse-radish peroxidase in enzymeimmunoassay. J. Immunoassay. 2, 187-204.

Bourget, L. and Chang, T. M. (1984). Artificial cell-microencapsulated phenylalanine ammonia-lyase. Appl. Biochem. Biotechnol. 10, 57-59.

Bourget, L. and Chang, T. M. (1986). Phenylalanine ammonialyase immobilized in microcapsules for the depletion of phenylalanine in plasma in phenylketonuric rat model. Biochim. Biophys. Acta. 883, 432-438.

Bourget, L. and Chang, T. M. (1989). Effects of oral administration of artificial cells immobilized phenylalanine ammonialyase on intestinal amino acids of phenylketonuric rats. Biomater. Artif. Cells Artif. Organs. 17, 161-181.

Chang, T. M., Bourget, L. and Lister, C. (1995). A new theory of enterorecirculation of amino acids and its use for depleting unwanted amino acids using oral enzyme-artificial cells, as in removing phenylalanine in phenylketonuria. Artif. Cells Blood Substit. Immobil. Biotechnol. 23, 1-21.

Delgado, C., Francis, G. E. and Fisher, D. (1992). The uses and properties of PEG-linked proteins. Crit. Rev. Ther. Drug Carrier Syst. 9, 249-304.

Fritz, R. R., Hodgins, D. S. and Abell, C. W. (1976). Phenylalanine ammonia-lyase. Induction and purification from yeast and clearance in mammals. J. Biol. Chem. 251, 4646-4650.

Gilbert, H. J. and Jack, G. W. (1981). The effect of proteinases on phenylalanine ammonia-lyase from the yeast Rhodotorula glutinis. Biochem. J. 199, 715-723.

Gilbert, H. J. and Tully, M. (1985). Protection of phenylalanine ammonia-lyase from proteolytic attack. Biochem. Biophys. Res. Commun. 131, 557-563.

Greenwald, R. B., Choe, Y. H,, McGuire, J. and Conover, C. D. (2003). Effective drug delivery by PEGylated drug conjugates. Adv. Drug Deliv. Rev. 55, 217-250.

Harris, J. M. and Chess, R. B. (2003). Effect of pegylation on pharmaceuticals. Nat. Rev. Drug Discovery. 2, 214-221.

Hershfield, M. S., Chaffee, S., Koro-Johnson, L., Mary, A., Smith, A. A. and Short, S. A. (1991). Use of site-directed mutagenesis to enhance the epitope-shielding effect of covalent modification of proteins with polyethylene glycol. Proc. Natl. Acad. Sci. USA. 88, 7185-7189.

Hoskins, D. S. (1968) The presence of a carbonyl group at the active site of L-phenylalanine ammonia-lyase. Biochem. Biophys. Res. Commun. 32, 246-253.

Hoskins, J. A. and Gray, J. (1982). Phenylalanine ammonialyase in the management of phenylketonuria: the relationship between ingested cinnamate and urinary hippurate in 
humans. Res. Commun. Chem. Pathol. Pharmacol. 35, 275282.

Hoskins, J. A., Jack, G., Wade, H. E., Peiris, R. J., Wright, E. C., Starr, D. J. and Stern, J. (1980). Enzymatic control of phenylalanine intake in phenylketonuria. Lancet. 23, 392-394.

Mehvar, R. (2000). Modulation of the pharmacokinetics and pharmacodynamics of proteins by polyethylene glycol conjugation. J. Pharm. Sci. 3, 125-136.

Monfardini, C., Schiavon, O., Caliceti, P., Morpurgo, M., Harris, J. M. and Veronese, F. M. (1995). A branched monomethoxypoly(ethylene glycol) for protein modification. Bioconjug. Chem. 6, 62-69.

Sarkissian, C. N., Shao, Z., Blain, F., Peevers, R., Su, H., Heft, R., Chang, T. M. and Scriver, C. R. (1999). A different approach to treatment of phenylketonuria: phenylalanine degradation with recombinant phenylalanine ammonia lyase. Proc. Natl. Acad. Sci. USA. 96, 2339-2344.

Scriver, C. R. and Kaufman, S. (2001). The metabolic and molecular bases of inherited disease. pp. 1667-1724. McGraw-Hill Press, New York.

Veronese, F. M. (2001). Peptide and protein PEGylation: a review of problems and solutions. Biomaterials. 22, 405-417.

Veronese, F. M., Caliceti, P., Schiavon, O. and Sergi, M. (2002). Polyethylene glycol-superoxide dismutase, a conjugate in search of exploitation. Adv. Drug Deliv. Rev. 54, 587-606.

Veronese, F. M., Monfardini, C., Caliceti, P., Schiavon, O., Scrawen, M. D. and Beer D. (1996). Improvement of pharmacokinetic, immunological and stability properties of asparaginase by conjugation to linear and branched monomethoxypoly (ethylene glycol). J. Control Release. 40, 199-209. 